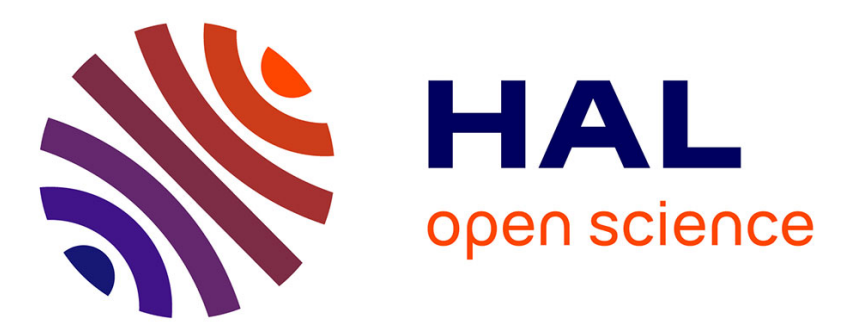

\title{
Orientation of the lateral semicircular canal in Xenarthra and its links with head posture and phylogeny
}

Florence Coutier, Lionel Hautier, Raphaël Cornette, Eli Amson, Guillaume

Billet

\section{- To cite this version:}

Florence Coutier, Lionel Hautier, Raphaël Cornette, Eli Amson, Guillaume Billet. Orientation of the lateral semicircular canal in Xenarthra and its links with head posture and phylogeny. European Journal of Morphology, 2017, 10.1002/jmor.20665 . hal-01484056

\section{HAL Id: hal-01484056 \\ https: / hal.sorbonne-universite.fr/hal-01484056}

Submitted on 6 Mar 2017

HAL is a multi-disciplinary open access archive for the deposit and dissemination of scientific research documents, whether they are published or not. The documents may come from teaching and research institutions in France or abroad, or from public or private research centers.
L'archive ouverte pluridisciplinaire HAL, est destinée au dépôt et à la diffusion de documents scientifiques de niveau recherche, publiés ou non, émanant des établissements d'enseignement et de recherche français ou étrangers, des laboratoires publics ou privés. 


\title{
Orientation of the lateral semicircular canal in Xenarthra and its links with head posture and phylogeny
}

\author{
Florence COUTIER ${ }^{1}$, Lionel HAUTIER ${ }^{2}$, Raphaël CORNETTE ${ }^{3}$, Eli AMSON $^{4}$, Guillaume \\ BILLET $^{1 *}$
}

1, Sorbonne Universités, CR2P, UMR CNRS 7207, Univ Paris 06, Muséum national d'Histoire naturelle, 8 rue Buffon, 75005 Paris, France.

2, Institut des Sciences de l'Evolution de Montpellier, Université Montpellier, CNRS, IRD, EPHE, Cc 064; place Eugène Bataillon, 34095 Montpellier Cedex 5, France.

3, Institut de Systématique, Évolution, Biodiversité (ISYEB) - UMR 7205 - CNRS, MNHN, UPMC, EPHE- Muséum national d'Histoire naturelle - Sorbonne Universités, 57 rue Cuvier, CP 30, 75005, Paris, France.

4, Humboldt-Universität, AG Morphologie und Formengeschichte, Bild Wissen Gestaltung - ein interdisziplinäres Labor \& Institut für Biologie, Philippstraße, 12/13, D-10115, Berlin, Germany.

*Corresponding author: billet@mnhn.fr

\begin{abstract}
The orientation of the semicircular canals of the inner ear in the skull of vertebrates is one of the determinants of the capacity of this system to detect a given rotational movement of the head. Past functional studies on the spatial orientation of the semicircular canals essentially focused on the lateral semicircular canal (LSC), which is supposedly held close to horizontal during rest and/or alert behaviours. However, they generally investigated this feature in only a few and distantly related taxa. Based on 3D models reconstructed from $\mu \mathrm{CT}$-scans of skulls, we examined the diversity of orientations of the LSC within one of the four major clades of placental mammals, i.e. the superorder Xenarthra, with a dataset that includes almost all extant genera and two extinct taxa. We observed a wide diversity of LSC orientations relative to the basicranium at both intra- and inter-specific scales. The estimated phylogenetic imprint on the orientation of the LSC was significant but rather low within the superorder, though some phylogenetic conservatism was detected for armadillos that were characterized by a strongly tilted LSC. A convergence between extant suspensory sloths was also detected, both genera showing a weakly tilted LSC. Our
\end{abstract}


preliminary analysis of usual head posture in extant xenarthrans based on photographs of living animals further revealed that the LSC orientation in armadillos is congruent with a strongly nosedown head posture. It also portrayed a more complex situation for sloths and anteaters. Finally, we also demonstrate that the conformation of the cranial vault and nuchal crests as well as the orientation of the posterior part of the petrosal may covary with the LSC orientation in Xenarthra. Possible inferences for the head postures of extinct xenarthrans such as giant ground sloths are discussed in the light of these results.

Key words: inner ear, bony labyrinth, morphometry, Mammalia, fossil

\section{Introduction}

The semicircular canal system of the inner ear is primarily specialized in the detection of rotational movements of the head and constitutes a major organ of balance in vertebrates (Sipla and Spoor, 2008). Accordingly, several aspects of its morphology were tentatively linked to locomotor behaviours (e.g., Spoor et al., 2007; Malinzak et al., 2012; Ekdale, 2016; David et al., 2016). Among these, the orientation of the semicircular canals is viewed as one of the determinants of the inner ear ability to detect rotational movements (David et al., 2010). Past studies have been most particularly interested in the orientation of the lateral semicircular canal (LSC) in tetrapods because of its potential link to head posture; they noted that this canal was often held close to horizontal or slightly tilted anteriorly upward during resting and/or alert behaviours (e.g., de Beer, 1947; Duijm, 1951; Hullar, 2006). The head posture in tetrapods exhibits an important diversity, be it at an interspecific level with animals showing differences in their head postures (e.g., de Beer, 1947; Duijm, 1951), or at an intraspecific or even intra-individual level, since an animal can adopt various head positions depending on its behavioural activity (i.e., at rest, during locomotion or in alert state) (Vidal et al., 1986; Erichsen et al., 1989; Nalley et al., 2015). 
The putative link between the LSC orientation in the skull and head posture has been proposed and investigated over the last century (e.g., Perez, 1922; Girard, 1923; Duijm, 1951; De Beer, 1947; Vidal et al., 1986; Brichta et al., 1988; Hullar, 2006), but recent studies suggested that its variation and complexity might have been overlooked (Taylor et al., 2009; Marugán-Lobón et al., 2013). To our knowledge, factors other than head posture, such as phylogeny and ontogeny, which could also be related to the LSC orientation within the skull have not been fully investigated. In most cases, this feature has only been studied in a few and distantly related taxa. In fact, as stated by Schmelzle et al. (2007: 94), associating LSC orientation and head posture still raises many questions. Despite these flaws, the orientation of the LSC is often used as a proxy for the head posture, especially in paleontological studies that seek to infer past "attitudes" of extinct vertebrates (e.g., Witmer et al., 2003; Chatterjee and Templin, 2004).

We provide here a first overview of the diversity of LSC orientations in Xenarthra, a major mammalian clade including 31 extant species (Gibb et al., 2016) with a wide range of morphological features and some very specialized locomotor behaviours and ecologies (e.g., subterranean, suspensory) (Vizcaíno and Loughry, 2008; and contributions therein). Extant Xenarthra comprised the strictly arboreal and suspensory sloths, the arboreal to terrestrial anteaters, and the armadillos that are mostly terrestrial and frequent diggers. In addition, the clade exhibits a rich fossil diversity, with very specialized forms such as the armored glyptodonts and giant ground sloths (Vizcaíno and Bargo, 2014). The small size of the clade permitted an almost exhaustive sampling of LSC orientations in extant Xenarthra. Based on these original data, we provide a first estimate of the potential phylogenetic signal of the orientation of this canal in one of the four major clades of placental mammals. We further compared the LSC orientation to observations on head postures in order to see if the former may relate to the latter and reflect behavioural traits in the clade. This analysis is completed by a study of the cranial shape in order to explore if other cranial features could covary with the LSC orientations. We then used these data to discuss the use of the 
LSC orientation in reconstructing head postures and locomotor behaviours in extinct forms such as the giant "ground sloth" Megatherium americanum.

\section{Materials and Methods}

\section{Specimens and CT-scanning}

Our database includes 48 skulls of Xenarthra belonging to 15 genera and 19 species, including the two fossil genera Megatherium $(\mathrm{n}=2)$ and Pelecyodon $(\mathrm{n}=1)$. A list of specimens and corresponding institutions is available in Table 1. Most of this database is common to that of Billet et al. (2015) to which have been added several armadillo specimens of Dasypus, Cabassous, Zaedyus, Chlamyphorus and the fossil sloth Pelecyodon. Only one extant genus is absent from our dataset, the poorly-known greater fairy armadillo Calyptophractus. Species identification for extant specimens was based on collection data, geographical origin, and cranial anatomy (Wetzel 1985; de Moraes-Barros et al. 2011; Hautier et al. 2014). Skulls were scanned by micro-Computed Tomography $(\mu \mathrm{CT})$ on X-ray platforms at the Museum national d'Histoire naturelle (France) in Paris (AST-RX platform); the Department of Engineering of the University of Cambridge (United Kingdom); the Steinmann Institut, University of Bonn (Germany); and the University of Montpellier (France). Details about scans and acquisition parameters are available in the SAppendix 1. Three-dimensional reconstructions of skulls and inner ears were performed from stacks of digital images $(\mu \mathrm{CT})$ with Mimics Research 17.0 (Materialize NV).

\section{Measurement of the LSC orientation}

In order to quantify the LSC orientation within the skull in a comparable manner across species, we measured the angular inclination of the LSC plane relative to the ventral surface of the basisphenoid, i.e., a well-identifiable plane of the skull extended along the antero-posterior axis. Indeed, this surface was relatively easy to identify on the medialmost virtual sagittal section of the 
skulls. The virtual sagittal section (i.e., the sagittal plane sensu stricto) was determined with the software Mimics Research 17.0 by moving along the parasagittal slices until finding the medialmost section that was best aligned with both the median palatine and median parietal sutures. Following this protocol, a line could be traced following the ventral edge of the basiphenoid on its medialmost section. The plane of the basisphenoid was then constructed with Mimics Research 17.0 as the plane passing through this medio-ventral line and orthogonal to the sagittal plane. The two Megatherium specimens were handled differently since this procedure was inapplicable due to the incompleteness of their skull. The basal part of the skull MNHN.F.PAM 276 is artificially reconstructed with mastic and did not permit to confidently trace the ventral line of its basisphenoid. Thus, the palate (i.e., its medial section) was exceptionally used as reference surface for this specimen. On the basis of observations made on other skulls of Megatherium americanum present at the MNHN (uncatalogued skulls on exhibit in the "galerie de paléontologie") and as it can be observed in many extant and fossil xenarthrans (pers. obs.), the palate and the basisphenoid were considered as roughly parallel. The second specimen of Megatherium, MNHN.F.TAR 1291, was only represented by an isolated temporal region (Billet et al., 2013), so we first measured the angle between i) a plane following the posterior part of the dorsal crest of the zygomatic arch and orthogonal to the sagittal plane and the plane of the LSC; ii) we also measured the angle between the plane of the dorsal crest of the zygomatic arch and the plane of the palate on MNHN.F.PAM 276 and then estimated the angle palate-LSC for MNHN.F.TAR 1291 based on this information.

The plane of the basisphenoid was then compared to the LSC plane, which was reconstructed as follows. For some specimens, the right and left LSCs of a same individual could be perfectly aligned in one plane defined as the LSC plane of reference. In ca. $56 \%$ of the specimens however, the LSC orientations were not exactly coplanar, e.g. the paired LSCs may slightly tilt up laterally. Such a deviation from coplanarity, which is rather common in mammals (Berlin et al., 2013), prevented a strict alignment of the two LSCs. For these specimens, a plane was specifically 
created and includes the three following points of the right LSC: centre of the lateral ampulla, centre of the LSC duct at its lateralmost extent and centre of the posterior junction between the LSC and the vestibule (S-Appendix 2). This protocol is thus very similar to the one used by Ekdale (2010), apart from the fact that we used the software Mimics Research 17.0.

For 13 out of the 16 specimens of extant sloths studied, the LSC could not be reduced to a single plane, most of its arc being at an angle with its vestibular roots. We then chose not to use the three points defined above since they were not the best descriptors of the orientation arc of the LSC. For these specimens, we only used the line passing by the distal planar part of the arc of the LSC in lateral view and discarded the two vestibular proximal extremities. The final plane used in the analyses was then defined as the plane passing by the latter line and being orthogonal to the sagittal plane.

The angle between the LSC plane and the basisphenoid (/palate) plane was measured with the software 3-Matics Research 9.0 (Materialize NV). The measured LSC-basisphenoid angle may take positive or negative values depending on the LSC orientation. The diversity and variation of LSC orientations (LSC-basisphenoid angle) were visualized with a Boxplot performed with the web tool BoxPlotR of Spitzer et al. (2014) available at http://boxplot.tyerslab.com/.

\section{Estimation of head posture in living xenarthrans}

In order to discuss potential links between the customary head posture (see Hullar, 2006) and LSC orientation in Xenarthra, we intended to provide a preliminary estimate of head inclination in living subjects. We hence used photographs and videos available online in public archiving platforms and websites (S-Appendix 3). We selected pictures of locomoting or resting animals, and whose head posture was not obviously influenced by an unusual activity or sniffing behaviour. Contrary to de Beer (1947), we did not specifically target for animals in an alert state because we found that this behaviour was particularly difficult to identify based solely on photographs or 
videos. Moreover, some or most xenarthrans may be characterized by a low acuity vision and colour blindness (Emerling and Springer, 2014), which may blur the concept of a visual alert state for these animals.

Only pictures showing a strict lateral view of a locomoting or standing animal, ideally on a flat horizontal surface, were selected. When the surface was not horizontal, a rotation was applied. A reference line marking the labial commissure (and thus approximately the orientation of the palate) was marked on the picture. Earth (i.e. ground) horizontal was underlined and the angle between the lines characterizing the labial commissure and the ground was measured using the software ImageJ $1.48 \mathrm{v}$. As explained in the results section, this protocol could only be successfully applied to armadillos (see an illustration in S-Appendix 4), and only qualitative observations were made for extant sloths and anteaters.

\section{Estimation of the phylogenetic signal of LSC orientations}

In order to visualize if the LSC orientation bears any phylogenetic signal, we mapped this feature on a pre-determined phylogeny of Xenarthra (see below) with the software Mesquite 3.0.3. (Maddison and Maddison, 2015) using linear parsimony as a reconstruction model. In addition, we used a randomization test ( $\mathrm{p}$ value) and the $\mathrm{K}$ index (Blomberg et al., 2003) to quantify the phylogenetic message carried by this continuous trait. This calculation was performed with Rgui 3.1.0 (R with Graphic User Interface; R Core Team, 2014) using the package Picante 1.6-2 (Kembel et al., 2010). When species and genera were documented by several specimens, we used the mean specific and generic value to perform the randomization test and calculate the $\mathrm{K}$ index.

Phylogenetic trees and divergence dates used for these analyses follow Gibb et al. (2016) for extant taxa, and Gaudin (2004) and Grass (2014: fig7) for extinct sloths (relationships and divergence dates) (NB: Croft 2013 was used for the age of the Santa Cruz Formation that yielded remains for Pelecyodon). However, when divergences dates were needed (only for the K index and 
correlation analyses with allometry, see below), only the timetree built by Grass (2014: fig7) was used, and a tritomy set for the genera Choloepus, Megatherium and Pelecyodon (S-Appendix 5). The tests and measurements of the phylogenetic signal have been performed at a specific level on the entire xenarthran sample only (extant taxa and extant + fossil taxa), but not on subsets of the xenarthran tree (e.g., cingulate clade) since the abovementioned analyses are sensitive to small taxonomic sampling (Blomberg et al., 2003; Münkemüller et al., 2012).

\section{Covariation between LSC orientation and cranial shape and size}

The LSC orientations were compared to the cranial shape using geometric morphometric methods. A set of 17 anatomical landmarks was placed on the posterior part of the reconstructed skulls with a special focus on the petrosal (its cerebellar face; other faces being concealed by other bones) (Tables 1-2). Several of these landmarks were inspired from Hautier et al. (2014) (landmarks $\mathrm{n}^{\circ} 1,4,5,7,8,9,10$ ). Only one half (right or left) of the posterior skull was used to place these landmarks (Fig. 1). Several specimens showed high suture closure levels (Rager et al., 2013), which limited the recognition of other classical anatomical landmarks. We tried to favour the use of landmarks of type I; landmarks of types II and III (Bookstein, 1991) were considered only when necessary to account for the morphological diversity of our sample.

Because of incomplete scanning or natural damage on the posterior part of the skull, we were only able to place the complete set of landmarks on 29 specimens (including the fossils Megatherium and Pelecyodon) out of the 48 initially considered (Tables 1-2). An extended dataset of 38 specimens was also considered using a reduced set of landmarks $(n=14$; limited to the posteriormost part of the skull) (Tables 1-2).

All landmarks were digitized with the interactive software ISE-Meshtools 1.0.4. (Lebrun, 2014; http://morphomuseum.com/meshtools). The analyses of these landmarks were performed with the interactive software package Morphotools 1.2. (Specht, 2007, Lebrun 2008). All 
configurations (sets of landmarks) were superimposed using the Procrustes method of generalized least squares superimposition (GLS scaled, translated, and rotated configurations so that the intralandmark distances were minimized) following the methods of Rohlf (1990) and Bookstein (1991).

In order to identify which part of the caudal cranium covaries with the LSC orientation, we performed a regression of skull shape on the LSC-basisphenoid angle, i.e., multivariate regression of the Procrustes residuals of the skull on the angular value of LSC orientation. We obtained a shape vector on which the specimens are projected. This vector captures the part of the shape variation that can be statistically explained as a function of the LSC orientation. This analysis was conducted with the software Morphotools (Lebrun, 2008).

Finally, the allometric influence on the LSC orientation has been investigated using the reduced dataset (14 landmarks, 38 specimens). The LSC angle values have been compared to the $\log$ centroid size of the landmark dataset. The correlation between these variables was first analysed without taking into account the potential phylogenetic effects (simple regression analysis on 38 specimens with the software Past 2.17 (Hammer et al., 2001)). Then, an analysis of phylogenetic independent contrasts (PICs, Felsenstein 1985) was performed using the PDAP module in Mesquite 3.0.3 (Maddison and Maddison, 2015) (on 18 species, using the specific mean for the two variables). For that matter, we used the same cladogram and age divergences as for the calculation of the $\mathrm{K}$ index (see above). The number of degrees of freedom for this analysis was fixed in accordance with the number of soft polytomies present in the cladogram (Garland \& Diaz-Uriarte, 1999) (i.e., 1 soft polytomy, 15 degrees of freedom).

\section{Results}

\section{Diversity and phylogenetic signal of LSC orientations}

The angle between the basisphenoid and the LSC clearly shows different ranges within the 
different orders and suborders of extant xenarthrans (Fig. 2 and 3). The whole range of LSC orientations is comprised between $-12^{\circ}$ (one specimen of Bradypus variegatus) and $53^{\circ}$ (Dasypus kappleri), thus covering more than $60^{\circ}$ of variation. The two genera of extant sloths, Bradypus and Choloepus, show the lowest values (always below $20^{\circ}$ and averaging $0-10^{\circ}$ in each species) while armadillos display the highest values (always above $20^{\circ}$ ). The anteaters show intermediate values between extant sloths and armadillos (mostly between 15 and $25^{\circ}$ ). The orientation of the LSC in the extinct sloths Megatherium and Pelecyodon is closer to that of armadillos than to extant sloths. The intraspecific variation for this angle can be rather high as documented for the extant brown throated three-toed sloths (Bradypus variegatus), for which eight specimens display more than $20^{\circ}$ of range of variation. With a similar number of specimens, the extant nine-banded armadillo also shows a high variation range, close to $16^{\circ}$. However, the latter species has a much smaller range comprised between the $25^{\text {th }}$ and $75^{\text {th }}$ percentiles than our sample of Bradypus variegatus. The five specimens of Tamandua tetradactyla show a range of variation that is clearly smaller than the one observed for Bradypus, and more similar to Dasypus novemcinctus (at least for the range between the $25^{\text {th }}$ and $75^{\text {th }}$ percentiles) (Fig. 2).

The $\mathrm{K}$ values show slightly different messages depending whether or not the fossils were included in the analyses. When only extant taxa were considered, the phylogenetic signal was significantly higher than random and the $\mathrm{K}$ value is only slightly below 1 (Table 3 ), thereby indicating a significant phylogenetic signal, which is only slightly weaker than what would be expected for an evolution under Brownian motion along the selected tree (Blomberg et al., 2003). When fossil sloth specimens were included in the phylogeny, the $\mathrm{K}$ value measured at the superordinal level clearly dropped (a factor of 1.5) but the signal remains significant $(\mathrm{p}<0.05)$ (Table 3). This difference seems to arise directly from the different angles measured in extant and extinct sloths: these taxa, yet closely related and with interwoven relationships along the studied tree, showed strong differences for the investigated trait (Fig. 4). 
The parsimonious mapping of the LSC orientation on the xenarthran tree gave an estimation of the ancestral state of the angle basiphenoid-LSC for Xenarthra close to $26.6^{\circ}$ (Fig. 4). The LSC orientation would then have drifted towards lower values in pilosans (lower in Folivora than in Vermilingua) and towards higher values in cingulates. The two extinct sloth genera would have secondarily acquired a more obliquely oriented LSC. Dasypus species depart from most other armadillos by showing an even higher inclination of the LSC, which constitutes an autapomorphic feature of long-nosed armadillos on this reconstruction.

\section{Observations of head postures in living xenarthrans}

The study of photographs and videos of living Xenarthra allowed us to make some quantitative and qualitative observations on their head postures. Gathering quantitative data was only possible for the cingulate clade that seems to be characterized by more stable/constant head postures than extant pilosans (see below). In the photographs selected for measurements, all armadillos invariably show a strongly inclined, nose-down head posture, somewhere between $25^{\circ}$ and $50^{\circ}$ (Table 4). We noted several differences between cingulate genera, with the long-nosed, pichi and three-banded armadillos showing the most nose-down head postures among the measured sample. Interestingly, these genera (Dasypus, Zaedyus and to a lesser degree Tolypeutes) also present the most strongly inclined LSC relative to the basisphenoid in our sample. This possible correspondence between LSC orientation and usual head posture in this group could however not be assessed statistically due to the low sample and the difficulty to measure precisely head posture using photographs only.

As mentioned above, no exploitable quantitative data of head postures could be collected on the photographs and videos available for sloths and anteaters. Overall, we observed a wide range of head motions for these animals. It is all the more significant among sloths that move vertically and horizontally along tree trunks and branches and hold their head in varying positions while moving. 
In addition, the horizontal plane was not easily determined in photographs of sloths, and further precludes taking measurement. In pictures where sloths were clearly stationed in vertical position, head up, they seemed to maintain their head in a horizontal or sub-horizontal posture (i.e., their labial commissure is horizontal, and so is the skull base).

Even if anteaters also showed a high amplitude of head movements while locomoting (possibly due to an intensive use of olfaction), we observed that Tamandua and Myrmecophaga show a tendency to maintain the posterior part of their skull close to or slightly below the horizontal plane. Due to its curvature, the snout was anteriorly directed towards the ground. Unfortunately, no exploitable data could be collected for the pygmy anteater Cyclopes.

\section{Covariation between LSC orientation and cranial shape and size}

The multivariate regressions of the shape of the caudal cranium by the LSC-basisphenoid angle indicated that the LSC orientation explains $37.27 \%$ and $40.83 \%$ of the variation of the cranial shape in the complete and incomplete datasets respectively (Fig. 5 and S-Appendix 6). In both analyses, this vector highly discriminates armadillos from extant sloths and anteaters whereas the two extinct sloths Megatherium and Pelecyodon sit in the middle of the graph. The pink fairy armadillo Chlamyphorus, characterized by a rather low LSC-basisphenoid angle, tend to depart from other armadillos by showing low Angle Shape Vector values. The analysis performed on the complete dataset indicates that xenarthrans with a large basisphenoid-LSC angle display a high occipital face, a wide foramen magnum, and a posterior part of the cranial vault (=dorsal edge of parietals) parallel to the basicranium as well as sinusoid, prominent, and thick nuchal crests (Fig. 5). Conversely, specimens with lower basisphenoid-LSC angle show a posteriorly tilted posterodorsal cranial vault and smooth nuchal crests. Overall, from the negative values of the ASV to the positive ones, the posterior part of the skull tends to become more anteriorly compressed (Fig. 5; see the varying distance between landmarks 2 and 12). In addition, the line joining the external aperture of 
the cochlear canaliculus and the external aperture of the vestibular aqueduct on the petrosal bone tend to tilt more anteriorly with an increasing LSC-basisphenoid angle whereas it is more vertical in specimens with a low angle. The analysis performed on the incomplete dataset suggests similar trends (see S-Appendix 6).

Chlamyphorus, as extant sloths, presents a posterior parietal tilt, which forms an open angle with the occipital face (Fig. 6). Megatherium and Pelecyodon, on the other hand show more resemblances with armadillos than with extant sloths, including a more acute angle between the posterodorsal cranial vault and the occipital face and thus a more protruding nuchal area (Fig. 6).

The regression analysis shows no significant relationship between the LSC-basisphenoid angle and the $\log$ centroid size of the back of the cranium $(n=38$ specimens $)\left(R^{2}=0.013357\right.$, $\mathrm{p}=0.4896)$. The analysis using PICs ( $\mathrm{n}=18$ species, 15 degrees of freedom; see Material and Methods $)$ also indicates a non-significant relationship $\left(\mathrm{R}^{2}=0.126, \mathrm{p}=0.147\right)$.

\section{Discussion}

\section{Diversity and phylogenetic signal of LSC orientation}

Our study revealed substantial variation of the LSC orientation at both intra- and interspecific levels. This is, to our knowledge, the first study that quantifies the amount of intraspecific variation for this character, which can reach up to $20^{\circ}$. Interestingly, the intraspecific variation in extant three-toed sloths was not exceedingly higher than in extant nine-banded armadillos, contrary to the variation in the shape of the semicircular canals (Billet et al., 2012). The intraspecific (inter-individual) variation that we observed in Xenarthra should be further compared with the large amount of bilateral variation in LSC orientation previously highlighted in mammals (Berlin et al., 2013). Both types of variations suggest that subtle differences in the orientation of this canal must be interpreted with caution. Apart from this substantial intraspecific variation, our survey of the interspecific diversity of LSC orientations in Xenarthra demonstrated that significant 
differences might still be detected between taxa.

Thanks to the inclusion of fossil sloths in our dataset, we showed that the two extant sloth genera Bradypus and Choloepus convergently evolved a weakly inclined lateral canal compared to the ventral surface of the basicranium. If the phylogenetic distance between the two extant sloth genera is widely accepted (Gaudin, 2004; Delsuc and Douzery, 2009; Slater et al., 2016; but see also Buckley et al., 2015), Bradypus and Choloepus show an impressive series of convergences, most of which may be related to their unique suspensory and sluggish behaviour. This includes reduced semicircular canals of the inner ear (Billet et al., 2013), limb modifications such as hooklike appendages (Nyakatura, 2012), and a specialized fur providing host environment for symbiotic algae (Aiello, 1985; Suutari et al., 2010). The significant difference of LSC orientation between extinct and extant sloths therefore adds to these previous observations.

The phylogenetic signal carried by the LSC orientation prove to be significant but rather low at a superordinal level when fossils were considered, which is partly induced by the convergent evolution of the inner ear morphology of extant sloths. Overall, this survey highlights the importance of quantifying variation at different taxonomic levels as well as to study the potential phylogenetic signal of LSC orientations. If, as we showed here, the phylogenetic signal is not really substantial in the evolution of this feature in xenarthrans, other factors should have played an important role on the generation of the observed diversity.

\section{Head posture and LSC orientation}

Preliminary comparisons between the head postures and LSC orientations allowed highlighting interesting trends within extant xenarthrans. Armadillos showed the most nose-down head posture, their snout being clearly directed towards the ground almost irrespective of their behaviour (locomoting, feeding, at rest, etc.). The vigilance state, which has been described in the nine-banded armadillo Dasypus novemcinctus as elevating the head with a nose pointing forward 
(McDonough and Loughry, 2013), might be an exception. When the vigilant pause is coupled with a sniff, Dasypus also seems to move its nose up and down (McDonough and Loughry, 2013). Therefore the alert state in Dasypus, and possibly in other armadillos as well, may not be associated with the same head posture(s) than when at rest or moving. Xenarthrans have a very poor eyesight (Emerling and Springer, 2014), and this vigilance or alert state in Dasypus (and allies?) may rely more on aural and olfactory detection of danger than in other mammals (McDonough and Loughry, 2013). Studying the head posture in relation to the LSC orientation during this vigilance or alert state is then questionable when dealing with armadillos, but such a comparison might still be insightful for other mammals that show alertness to sight (e.g., de Beer, 1947; Vidal et al., 1986).

If head postures and behaviours still remain to be better understood and quantified in armadillos, it is all the most interesting that cingulates show the greatest values of basisphenoidLSC angle in our sample of extant xenarthrans. If their LSC was to be oriented horizontally, the posture of their skull would match nicely our observations of nose-down head postures for extant individuals (Fig. 7). This would therefore argue in favour of a usual head posture coinciding with a LSC held near earth-horizontal (Hullar, 2006). The head postures of extant sloths and anteaters were more difficult to characterize based on our photographic observations because they tend to show a wide range of head positions during locomotion. Goffart (1971) and Clauss (2004) noticed that extant sloths likely rest in an upright sitting posture, squatting in a tree fork or embracing a small trunk. We observed that sloths usually adopt a rather horizontal head posture (i.e., skull base horizontal) in such a resting position, which would implied that their LSC is maintained near earthhorizontal. In addition, anteaters may show a mean position of LSC near earth-horizontal while locomoting. Accordingly, we can hypothesize that certain types of head postures in sloths and anteaters coincide, to some extent, with a (sub)horizontal LSC (Fig. 7). However, more quantitative and qualitative behavioural data are still needed to pinpoint when and how often a horizontal LSC position is reached, as well as to further test the existence of a link between LSC orientations and 
head posture in these groups.

Recent studies have pointed out the probable large intraspecific variability of LSC orientations (both intra- and inter-individually) (Taylor et al., 2009; Berlin et al., 2013), which is confirmed by our observations. Altogether, these results suggest that the LSC orientation within the skull cannot be used as a precise indicator of a given or of usual head posture(s) in mammals. In addition to getting better behavioural data, it also becomes timely to better understand physiological implications related to the relative position of the LSC with respect to the ground (Schmelzle et al. 2007). Canal morphology has been described as being primarily arranged for the detection of head movements (Jeffery and Cox, 2010). In line with this hypothesis, de Beer (1947) proposed that the LSC is held close to earth-horizontal, so it can be more sensitive to yaw movements during alertness. A greater activation of the LSC during yaw movements may indeed occur (David et al., 2010), though these movements may not only be restricted to alertness. For these reasons, Spoor and Zonnefeld (1998: 245) suggested almost 20 years ago, that instead of focusing on the static head postures of animals in a given situation, it could be more pertinent to study the potential correspondence between the LSC orientation and the predominant plane of natural yaw movements of the head. This remains to be done for all mammalian groups, xenarthrans included, within a kinematic study aiming at integrating both static head postures and preferential yaw movements along with LSC orientations.

Compared to sloths and anteaters, the small range of head postures in armadillos is really distinctive. In addition to possible behavioural reasons (an arboreal lifestyle might impose more frequent and more diverse head movements in three dimensions), a more anatomical explanation can also be proposed. A syncervical (i.e. fused cervical vertebrae) is invariably present in extant armadillos, though its composition and conformation may vary. This structure most likely increases the out-lever force during head-lift digging in these fossorial animals but may also stabilize/stiffen their neck and head (van Buren and Evans, 2016), which would be congruent with the lesser 
variability observed in their head postures and movements.

\section{Covariation of skull shape and LSC orientation}

Our analyses showed that several parts of the posterior part of the cranium covary with the LSC orientation, including the posteroventral part of the cerebellar face of the petrosal. The LSC and the bony labyrinth of the inner ear as a whole are housed within the petrosal bone, and this covariation patterns could indicate that the LSC orientation is partly linked to some aspects of the petrosal ontogenesis. The fact that the petrosal rotates during ontogeny has been documented for humans more than a decade ago (Jeffery and Spoor, 2002), but it was not until recently that ontogenetic data on the LSC orientation in humans were collected. Lyu et al. (2016) demonstrated that the human ASC and LSC tilt anteriorly simultaneously after birth until adult age. Unfortunately, to our knowledge, no data is known for other mammals and prevents any extrapolation of this trajectory to the diversity of LSC orientations seen in xenarthrans. It is however noteworthy that the three-toed sloth Bradypus, which shows the most anteriorly tilted LSC, is often viewed as a neotenic form especially regarding its cranial features (Patterson et al., 1992; Gaudin, 1995; McAfee, 2014; Hautier et al., 2016). Ontogenetic studies of LSC and petrosal spatial arrangements in xenarthrans may therefore constitute a promising way of research in order to understand this diversity. Even if an allometric relation between the skull size and the LSC orientation seems to be non-significant at an interspecific level, such an ontogenetic study may help to better characterize the interplay of possible intraspecific allometric trends.

Finally, we also showed that the protrusion of the nuchal area and the orientation of the posterior cranial vault covary with the LSC orientation. Neck muscles take their origin onto the nuchal crests and surrounding areas (e.g., recti capitis dorsalis major and minor, semispinalis capitis) (Evans \& de Lahunta 2012 and Barone 2000). The greater protrusion of this crest in xenarthrans associated with a more oblique LSC may thus indicate a greater development of the 
neck musculature. Interestingly, several studies (Graf et al., 1995; Khan and Chang, 2013) already proposed that the coordination of head and neck movements involves an intricate relationship between the SCs and the activation of neck muscles. However, the existence of biomechanical causal effects linking the orientation of the LSC and the development of neck musculature is unclear. In any case, it is particularly intriguing that extinct sloths and most extant armadillos share highly oblique LSCs and well-marked nuchal crests in spite of their distant phylogenetic relationships. This situation contrasts with what we observed for extant sloths, which display weakly oblique LSC and, together with the pink-fairy armadillo, a posteriorly tilted cranial vault (i.e., an obtuse angle between the posterior part of the cranial vault and the occipital face). Whether these aspect may in turn be related to different head postures certainly needs to be investigated biomechanically.

\section{Head posture in extinct xenarthrans}

Our analyses suggested that no clear-cut relationship could be easily retrieved between the LSC orientation and head posture in Xenarthra. As a result, the LSC can only be used as an imprecise indicator of the head posture of extinct taxa in Xenarthra as well as in mammals as a whole (Taylor et al., 2009; Berlin et al., 2013). The Figure 6 shows what could be the head inclination in fossil sloths if the LSC were held horizontal. This view confirms that the LSC is oriented very obliquely in the skull of Megatherium and Pelecyodon which suggests that the use of the palate to contrast the LSC orientation in the former genus (see Material and Methods) did not affect significantly the results. Based on this reconstruction, head posture in extinct sloths would be close to that of extant armadillos. However, as extant pilosans, fossil folivorans did not present a syncervical, which may have allowed them to display a wider range of head postures than extant cingulate. Light must be shed upon the relationships between head postures and movements, behaviour, and LSC orientation if one wants to be able to draw more definite conclusions on these 
aspects. On the other hand, the conformation of nuchal area may provide an independent way to assess the usual head posture of extinct xenarthrans. It remains to be tested whether or not a protruding nuchal area could indicate a nose-down head posture (see above). If this is the case, it would further point to Megatherium and Pelecyodon having an armadillo-like usual head posture. Such a head posture in giant extinct sloths would add new elements to the long-standing debate on their locomotion (e.g., Casinos, 1996; Blanco and Czerwogonora, 2003). A usual nose-down orientation of the head in Megatherium would be hardly compatible with a bipedal stance as it implies a high angle between the skull and the neck vertebrae. It would thus argue in favour of a quadrupedal locomotion, as suggested by recent studies on postcranial and track data (McDonald, 2007).

\section{Acknowledgments}

We thank M. García-Sánz, G. Clément, A. Balzeau, and F. Goussard (AST-RX platform, Muséum national d'Histoire naturelle, Paris, France); S. Ladevèze, C. Selva, C. de Muizon, G. Véron, A. Verguin, V. Pernègre and C. Argot (MNHN, Paris, France); MRI platform and R. Lebrun (ISEM, Montpellier); I. Ruf (University of Bonn, Germany); R. Hutterer (ZFMK [Zoologisches Forschungsmuseum Alexander Koenig], Bonn, Germany); A. Heaver (Department of Engineering, University of Cambridge, United Kingdom); and M. Lowe (Museum of Zoology, University of Cambridge, United Kingdom) for providing access to specimens and/or helping with the CTscanning and 3D softwares. This work has benefited from an "Investissements d'Avenir" grant managed by Agence Nationale de la Recherche, France (CEBA, ref. ANR-10-LABX-25-01). EA was supported by the Alexander von Humboldt Foundation. Part of the experiments were performed using the $\mu$-CT facilities of the MRI platform and of the LabEx CeMEB. We are very grateful to two anonymous reviewers whose comments helped to improve the manuscript. Finally, we warmly 
thank J. Schultz (Univ. Chicago; USA), C. Pfaff (Univ. Vienna; Austria) and R. Schellhorn (Univ. Bonn; Germany) for organizing this Special Issue and the "Show me your ear" Symposium at ICVM11.

\section{References}

Aiello A. 1985. Sloth hair: unanswered questions. In: Montgomery GG, editor. The Evolution and Ecology of Armadillos, Sloths and Vermilinguas. Washington, DC: Smithsonian Institution Press. pp. 213-218.

Barone R. 2000. Anatomie comparée des mammifères domestiques. Tome 2, Arthrologie et myologie. Vigot, Paris, 1066 p.

Berlin JC, Kirk EC, Rowe TB. 2013. Functional Implications of Ubiquitous Semicircular Canal Non-Orthogonality in Mammals. PloS One 8:e79585.

Billet G, Hautier L, Asher RJ, Schwarz C, Crumpton N, Martin T, Ruf I. 2012. High morphological variation of vestibular system accompanies slow and infrequent locomotion in three-toed sloths. Proceedings of the Royal Society of London B 279:3932-3939.

Billet G, Germain D, Ruf I, de Muizon C, Hautier L. 2013. The inner ear of Megatherium and the evolution of the vestibular system in sloths. Journal of Anatomy 223:557-567.

Billet G, Hautier L, Lebrun R. 2015. Morphological diversity of the bony labyrinth (inner ear) in extant xenarthrans and its relation to phylogeny. Journal of Mammalogy 96(4):658-672. 
Blanco RE, Czerwonogora A. 2003. The gait of Megatherium Cuvier 1796 (Mammalia, Xenarthra, Megatheriidae). Senckenbergian Biologica 83:61-68.

Blomberg SP, Garland T, Ives AR. 2003. Testing for phylogenetic signal in comparative data : behavioral traits are more labile. Evolution 57(4):717-745.

Bookstein FL. 1991. Morphometric tools for landmark data : Geometry and Biology. Cambridge University Press.

Brichta AM, Acuna DL, Peterson EH. 1988. Planar relations of semicircular canals in awake, resting turtles, Pseudemys scripta. Brain, behavior and evolution 32(4):236-245.

Buckley M, Fariña RA, Lawless C, Tambusso PS, Varela L, Carlini AA, Powell JE, Martinez JG. 2015. Collagen sequence analysis of the extinct giant ground sloths Lestodon and Megatherium. PloS one10(11):e0139611.

Casinos A. 1996. Bipedalism and quadrupedalism in Megatherium: an attempt at biomechanical reconstruction. Lethaia 29:87-96.

Chatterjee S, Templin RJ. 2004. Posture, locomotion, and paleoecology of pterosaurs. Geological Society of America, Special Paper 376:1-64.

Clauss M. 2004. The potential interplay of posture, digestive anatomy, density of ingesta and gravity in mammalian herbivores: Why sloths do not rest upside down. Mammal Review 34(3):241- 
Croft DA. 2013. What constitutes a fossil mammal community in the early Miocene Santa Cruz formation?. Journal of Vertebrate Paleontology 33(2):401-409.

David R, Droulez J, Allain R, Berthoz A, Janvier P, Bennequin D. 2010. Motion from the past. A new method to infer vestibular capacities of extinct species. Comptes Rendus Palevol 9:397-410.

David R, Stoessel A, Berthoz A, Spoor F, Bennequin D. 2016. Assessing morphology and function of the semicircular duct system: introducing new in-situ visualization and software toolbox. Scientific Reports 6:32772.

de Beer GR. 1947. How animals hold their head. Proceedings of the Linnean Society of London 159(2):125-139.

de Moraes-Barros N, Silva JAB, Morgante JS. 2011. Morphology, molecular phylogeny, and taxonomic inconsistencies in the study of Bradypus sloths (Pilosa: Bradypodidae). Journal of Mammalogy 92:86-100.

Delsuc F, Douzery EJP. 2009. Armadillos, anteaters and sloths (Xenarthra). In: Hedges SB, Kumar S, editors. The Time Tree of Life. Oxford: Oxford University Press. pp. 475-478.

Duijm M. 1951. On the head posture in birds and its relation to some anatomical features. II. Proceedings of the Koninklijke Nederlandse Akademie van Wetenschappen Series C 54:260-271. 
Ekdale EG. 2010. Ontogenetic variation in the bony labyrinth of Monodelphis domestica (Mammalia: Marsupialia) following ossification of the inner ear cavities. The Anatomical Record 293(11):1896-1912.

Ekdale EG. 2016. Form and function of the mammalian inner ear. Journal of Anatomy 228(2):324337.

Emerling CA, Springer MS. 2015. Genomic evidence for rod monochromacy in sloths and armadillos suggests early subterranean history for Xenarthra. Proceedings of the Royal Society of London B 282:20142192.

Erichsen JT, Hodos W, Evinger C, Bessette BB, Phillips SJ. 1989. Head orientation in pigeons: postural, locomotor and visual determinants. Brain, behavior and evolution 33(5):268-278.

Evans HE, de Lahunta A. 2012. Miller's Anatomy of the Dog. Saunders, St Louis, 850 p.

Felsenstein J. 1985. Phylogenies and the comparative method. American Naturalist 125:1-15.

Garland T, Diaz-Uriarte R. 1999. Polytomies and phylogenetically independent contrasts: examination of the bounded degrees of freedom approach. Systematic Biology 48:547-558.

Gaudin TJ. 1995. The ear region of edentates and the phylogeny of the Tardigrada (Mammalia, Xenarthra). J Vertebr Paleontol 15:672-705.

Gaudin TJ. 2004. Phylogenetic relationships among sloths (Mammalia, Xenarthra, Tardigrada): the 
craniodental evidence. Zoological Journal of the Linnean Society 140:255-305.

Gibb GC, Condamine FL, Kuch M, Enk J, Moraes-Barros N, Superina M, Poinar HN, Delsuc F. 2016. Shotgun mitogenomics provides a reference phylogenetic framework and timescale for living xenarthrans. Molecular Biology and Evolution 33(3):621-642.

Girard L. 1923. Le plan des canaux semicirculaires horizontaux considéré comme plan horizontal de la tête. Bull Mem Soc Anthrop (Paris) 14:14.

Goffart M. 1971. Function and form in the sloth. Oxford: Pergamon Press.

Graf W, De Waele C, Vidal P. 1995. Functional anatomy of the head-neck movement system of quadrupedal and bipedal mammals. Journal of Anatomy 186:55-74.

Grass AD. 2014. Inferring lifestyle and locomotor habits of extinct sloths through scapula morphology and implications for convergent evolution in extant sloths. Ph.D. thesis, University of Iowa.

Hammer Ø, Harper DAT, Ryan PD. 2001. PAST: paleontological statistics software package for education and data analysis. Palaeontologica Electronica 4:9.

Hautier L, Billet G, Eastwood B, Lane J. 2014. Patterns of morphological variation of extant sloth skulls and their implication for future conservation efforts. The Anatomical Record 297:979-1008.

Hautier L, Rodrigues HG, Billet G, Asher RJ. 2016. The hidden teeth of sloths: evolutionary 
vestiges and the development of a simplified dentition. Scientific Reports 6:27763.

Hullar TE. 2006. Semicircular canal geometry, afferent sensitivity, and animal behavior. The Anatomical Record 288:466-472.

Jeffery N, Spoor F. 2002. Brain size and the human cranial base : A prenatal perspective. American Journal of Physical Anthropology 118:324-340.

Jeffery N, Cox PG. 2010. Do agility and skull architecture influence the geometry of the mammalian vestibulo-ocular reflex?. Journal of Anatomy 216(4):496-509.

Kembel SW, Cowan PD, Helmus MR, Cornwell WK, Morlon H, Ackerly DD, Blomberg SP, Webb CO. 2010. Picante: R tools for integrating phylogenies and ecology. Bioinformatics 26:1463-1464.

Khan S, Chang R. 2013. Anatomy of the vestibular system: a review. NeuroRehabilitation 32(3):437-443.

Lebrun R. 2008. Evolution and development of the strepsirrhine primate skull. Ph.D. thesis, University Montpellier II, University of Zürich, Montpellier, Zürich.

Lebrun, R. 2014. ISE-MeshTools software. http://morphomuseum.com/meshtools . Accessed 1 February 2015.

Lyu H-Y, Chen K-G, Yin D-M, Hong J, Yang L, Zhang T-Y, Dai P-D. 2016. The Age-Related Orientational Changes of Human Semicircular Canals. Clinical and Experimental 
Otorhinolaryngology 9(2):109-115.

Maddison WP, Maddison DR. 2015. Mesquite: a modular system for evolutionary analysis. $\underline{\text { http://mesquiteproject.org }}$

Malinzak MD, Kay RF, Hullar TE. 2012. Locomotor head movements and semicircular canal morphology in primates. Proceedings of the National Academy of Sciences 109(44):17914-17919.

Marugán-Lobón J, Chiappe LM, Farke AA. 2013. The variability of inner ear orientation in saurischian dinosaurs: testing the use of semicircular canals as a reference system for comparative anatomy. PeerJ 1:e124.

McAfee RK. 2014. Dental anomalies within extant members of the mammalian Order Pilosa. Acta Zoologica 96(3):301-311.

McDonald HG. 2007. Biomechanical inferences of locomotion in ground sloths: integrating morphological and track data. New Mexico Museum of Natural History and Science Bulletin 42:201-208.

McDonough CM, Loughry WJ. 2013. The nine-banded armadillo: a natural history (Vol. 11). University of Oklahoma Press, 323 pp.

Münkemüller T, Lavergne S, Bzeznik B, Dray S, Jombart T, Schiffers K, Thuiller W. 2012. How to measure and test phylogenetic signal. Methods in Ecology and Evolution 3(4):743-756. 
Nalley TK, Grider-Potter N. 2015. Functional morphology of the primate head and neck. American Journal of Physical Anthropology 156(4):531-542.

Nyakatura JA. 2012. The convergent evolution of suspensory posture and locomotion in tree sloths. Journal of Mammalian Evolution 19:225-234.

Patterson B, Segall W, Turnbull WB, Gaudin TJ. 1992. The ear region in Xenarthrans (= Edentata: Mammalia) Part II. Pilosa (sloths, anteaters), palaeanodonts, and a miscellany. Fieldiana Geology, New Series 24:1-79.

Perez F. 1922. Craniologie vestibienne, ethnique et zoologique. Bull Mem Soc Anthrop (Paris) $13: 16$

R Core Team, 2014. R: A language and environment for statistical computing. R Foundation for Statistical Computing, Vienna, Austria. URL http://www.R-project.org/.

Rager L, Hautier L, Forasiepi A, Goswami A, Sánchez-Villagra MR. 2014. Timing of cranial suture closure in placental mammals: Phylogenetic patterns, intraspecific variation, and comparison with marsupials. Journal of Morphology 275(2):125-140.

Rohlf FJ, Slice D. 1990. Extensions of the Procrustes method for the optimal superimposition of landmarks. Systematic Biology 39(1):40-59.

Schmelzle T, Sánchez-Villagra MR, Maier W. 2007. Vestibular labyrinth diversity in diprotodontian marsupial mammals. Mammal Study 32:83-97. 
Sipla J, Spoor F. 2008. The physics and physiology of balance. In: Thewissen JGM, Nummela S, editors. Sensory evolution on the threshold: adaptations in secondarily aquatic vertebrates. Berkeley, CA: University California Press. pp 227-232.

Slater GJ, Cui P, Forasiepi AM, Lenz D, Tsangaras K, Voirin B, ... Greenwood AD. 2016. Evolutionary relationships among extinct and extant sloths: the evidence of mitogenomes and retroviruses. Genome Biology and Evolution, 8(3), 607-621.

Specht M. 2007. Spherical surface parameterization and its application to geometric morphometric analysis of the braincase. Ph.D. thesis, University of Zürich Irchel, Zürich, Switzerland.

Spitzer M, Wildenhain J, Rappsilber J, Tyers M. 2014. BoxPlotR: a web tool for generation of box plots. Nature methods 11(2):121-122.

Spoor F, Zonnefeld F. 1998. Comparative Review of the Human Bony Labyrinth. Yearbook of Physical Anthropology 41:211-251.

Spoor F, Garland Jr T, Krovitz G, Ryan TM, Silcox MT, Walker A. 2007. The primate semicircular canal system and locomotion. Proceedings of the National Academy of Sciences 104:10808-10812.

Suutari M, Majaneva M, Fewer DP, Voirin B, Aiello A, Friedl T, ... Blomster J. 2010. Molecular evidence for a diverse green algal community growing in the hair of sloths and a specific association with Trichophilus welckeri (Chlorophyta, Ulvophyceae). BMC Evolutionary Biology 10(1):1. 
Taylor MP, Wedel MJ, Naish D. 2009. Head and neck posture in sauropod dinosaurs inferred from extant animals. Acta Palaeontologica Polonica 54(2):213-220.

VanBuren CS, Evans DC. 2016. Evolution and function of anterior cervical vertebral fusion in tetrapods. Biological Reviews. doi: 10.1111/brv.12245

Vizcaíno SF, Bargo MS. 2015. Loss of ancient diversity of xenarthrans and the value of protecting extant armadillos, sloths and anteaters. Edentata 15:27-38.

Vizcaíno SF, Loughry WJ. 2008. Biology of the Xenarthra. University Press of Florida.

Vidal PP, Graf W, Berthoz A. 1986. The orientation of the cervical vertebral column in unrestrained awake animals. Experimental Brain Research 61(3):549-559.

Wetzel RM. 1985. The identification and distribution of recent Xenarthra (= Edentata). In: Montgomery GG, editor. The Evolution and Ecology of Armadillos, Sloths and Vermilinguas. Washington, DC: Smithsonian Institution Press. pp. 5-21.

Witmer LM, Chatterjee S, Franzosa J, Rowe T. 2003. Neuroanatomy of flying reptiles and implications for flight, posture and behaviour. Nature 425:950-953.

\section{Figure captions}



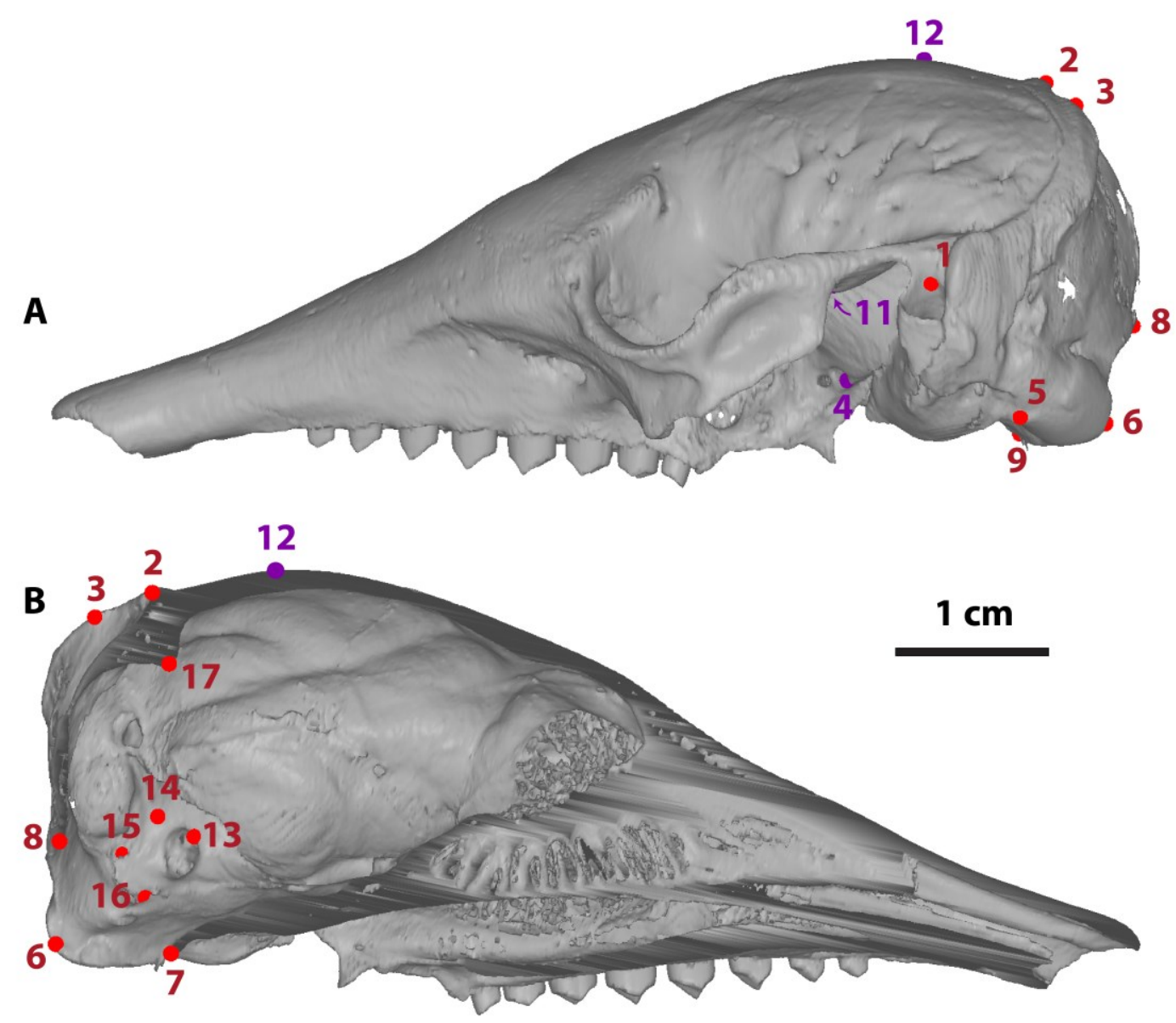

Figure 1. Landmarks digitized on the caudal cranium of Xenarthra, illustrated on a 3D model of Zaedyus pichyi. Purple landmarks represent those excluded from the reduced landmark dataset (see Table 2 for a description of landmarks and Table 1 and S-Appendix 1 for details on digitized specimens and datasets). NB: landmark $n^{\circ} 10$ is hidden but close to the $\mathrm{n}^{\circ} 9$. 


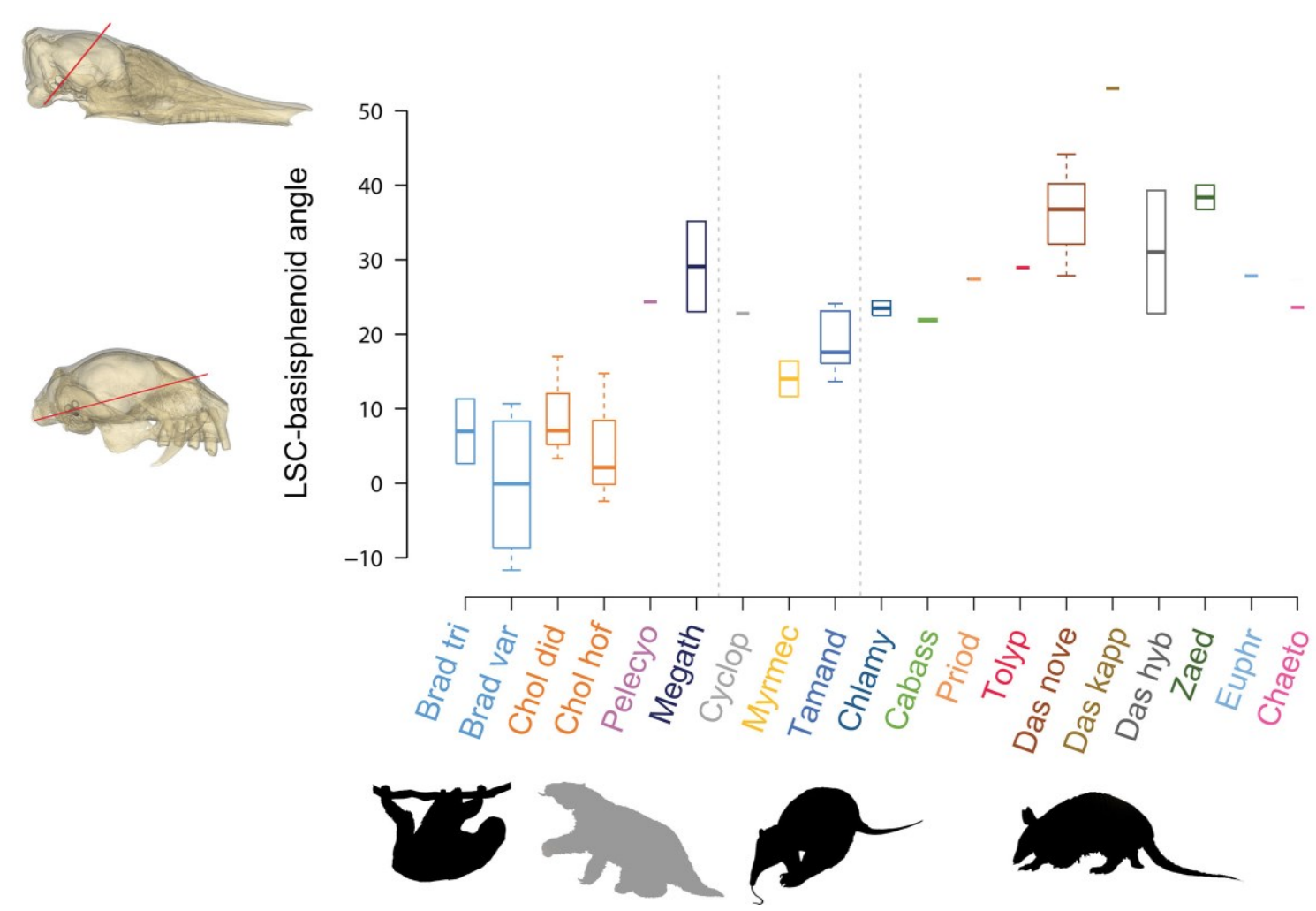

Figure 2. Boxplot of LSC orientations (LSC-basisphenoid angle) in Xenarthra. Center lines show the medians; box limits indicate the 25th and 75th percentiles as determined by $\mathrm{R}$ software; whiskers extend to minimum and maximum values; width of the boxes is proportional to the square root of the sample size $(\mathrm{n}=2,8,3,3,1,2,1,2,5,2,2,1,2,8,1,1,2,1,1)$. Made from Spitzer et al (2014; Nature Methods) at http://boxplot.tyerslab.com/ . Dashed lines separate the three main clades of xenarthrans. Abbreviations: Brad tri, Bradypus tridactylus; Brad var, Bradypus variegatus; Chol did, Choloepus didactylus; Chol hof, Choloepus hoffmani; Pelecyo, Pelecyodon cristatus; Megath, Megatherium sp.; Cyclop, Cyclopes didactylus; Myrmec, Myrmecophaga tridactyla; Tamand, Tamandua tetradactyla; Chlamy, Chlamyphorus truncatus; Cabass, Cabassous unicinctus; Priod, Priodontes maximus; Tolyp, Tolypeutes matacus; Das nove, Dasypus novemcinctus; Das kapp, Dasypus kappleri; Das hyb, Dasypus hybridus; Zaed, Zaedyus pichiy; Euphr, Euphractus sexcinctus; Chaeto, Chaetophractus vellerosus. 

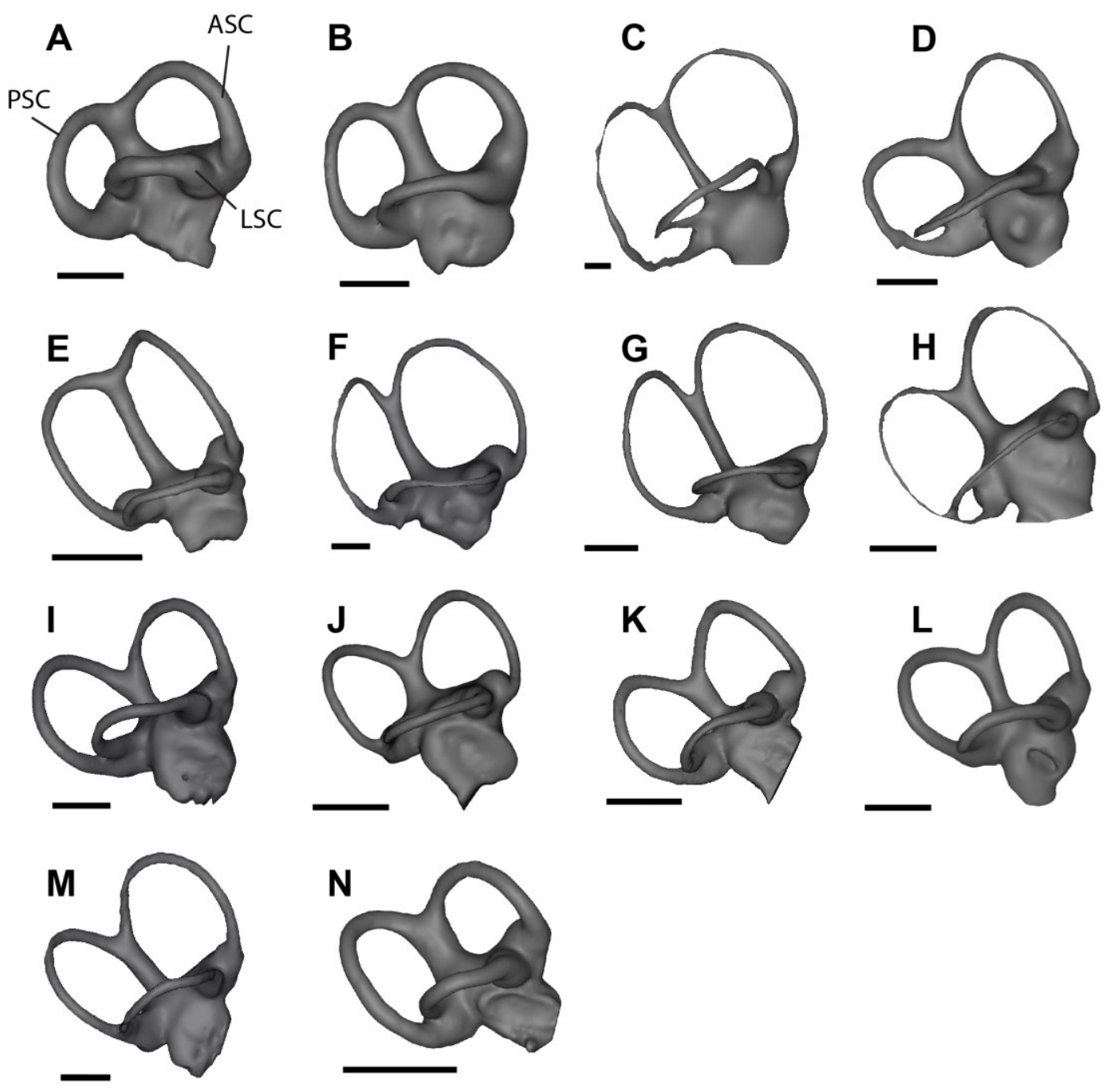

Figure 3. Lateral profile views of the right lateral semicircular canal (LSC) in selected xenarthran taxa investigated in this paper, when the basisphenoid (not depicted) is oriented horizontally. A, Bradypus tridactylus, UMZC E21; B, Choloepus hoffmanni UMZC E115; C, Megatherium americanum, MNHN.F.PAM 276; D, Pelecyodon cristatus, MNHN.F.SCZ 204; E, Cyclopes didactylus, UMZC E621; F, Myrmecophaga tridactyla, UMZC E562; G, Tamandua tetradactyla, UMZC E582; H, Dasypus novemcinctus, LH collection; I, Euphractus sexcinctus, ZFMK 79577; J, Chaetophractus vellerosus, ZFMK 59455; K, Zaedyus pichyi, MNHN.CG 1917-135; L, Cabassous unicinctus, MNHN.CG 1953-457; M, Priodontes maximus, ZFMK 76383; N, Chlamyphorus truncatus, UMZC E1201. Scale-bar $=2 \mathrm{~mm}$. See S-Appendix 1 for more information on sampled 
specimens.
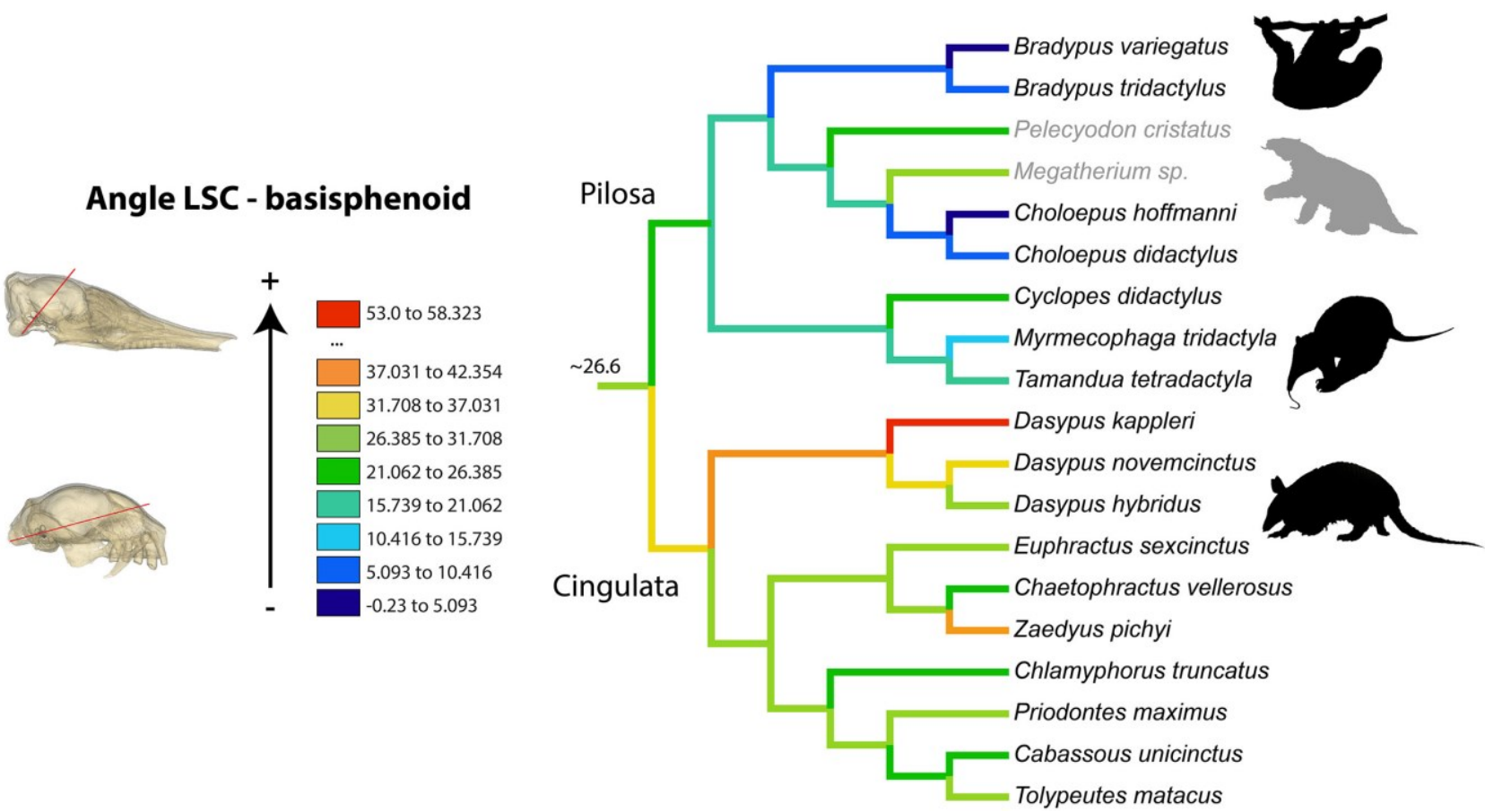

Figure 4. Evolution of the lateral semicircular canal (LSC) orientation relative to the basisphenoid bone in Xenarthra. Illustration of the most parsimonious hypothesis mapped on a composite cladogram of Xenarthra (see Material and Methods), indicating the ancestral value reconstructed for the node Xenarthra. Fossil taxa appear in grey. 


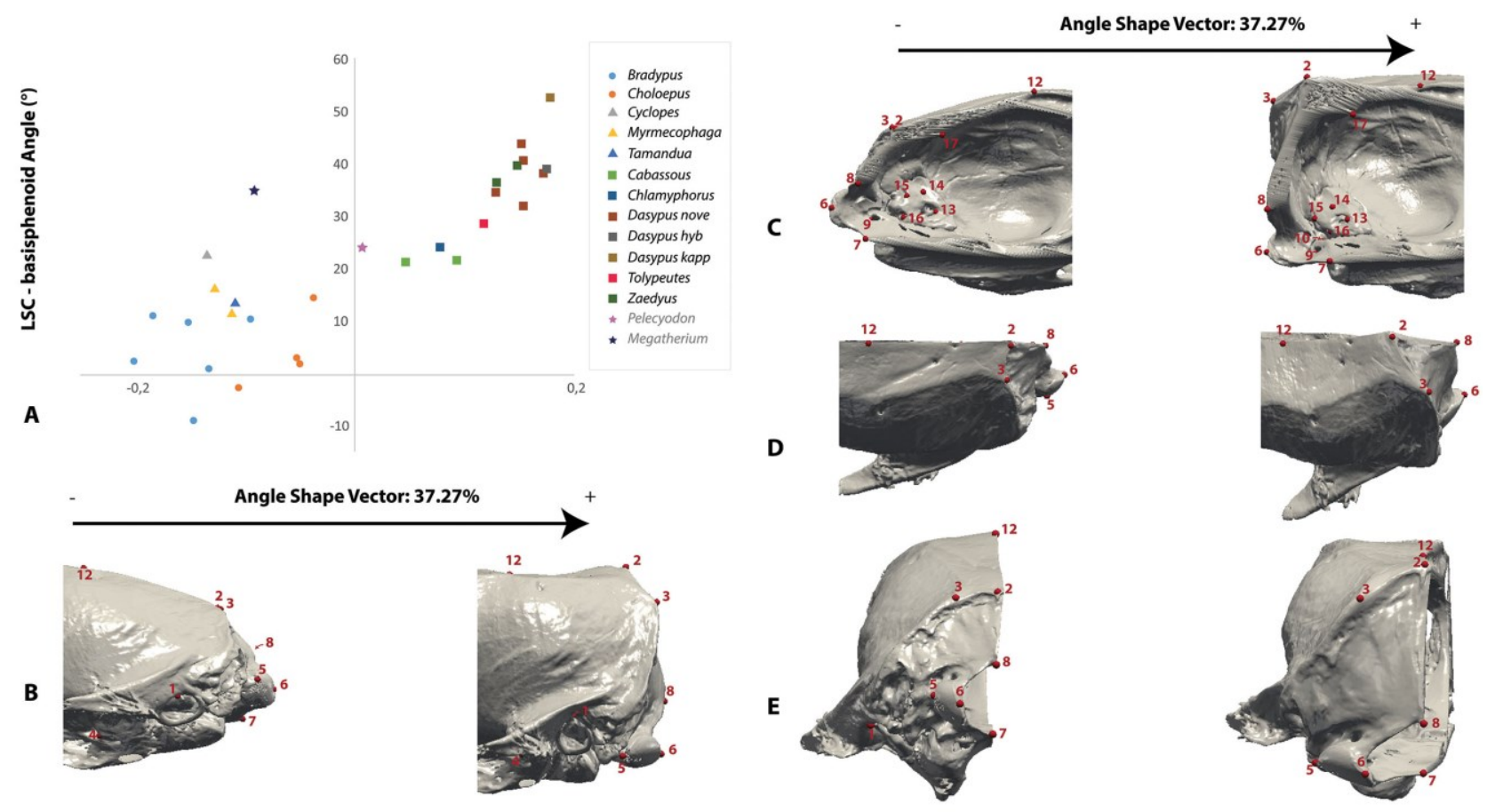

Figure 5. Covariation between the LSC orientation and caudal cranial shape in the 17 landmark dataset. A, shape differentiation of the caudal cranium explained by variation in the LSC orientation (see Material and Methods). B, C, D, and E, virtual deformations associated with variations of the LSC-basisphenoid angle, on the extreme sides of the Angle Shape Vector axis, in lateral, medial, dorsal and posterior views respectively. Taxonomic abbreviations same as in Figure 2.

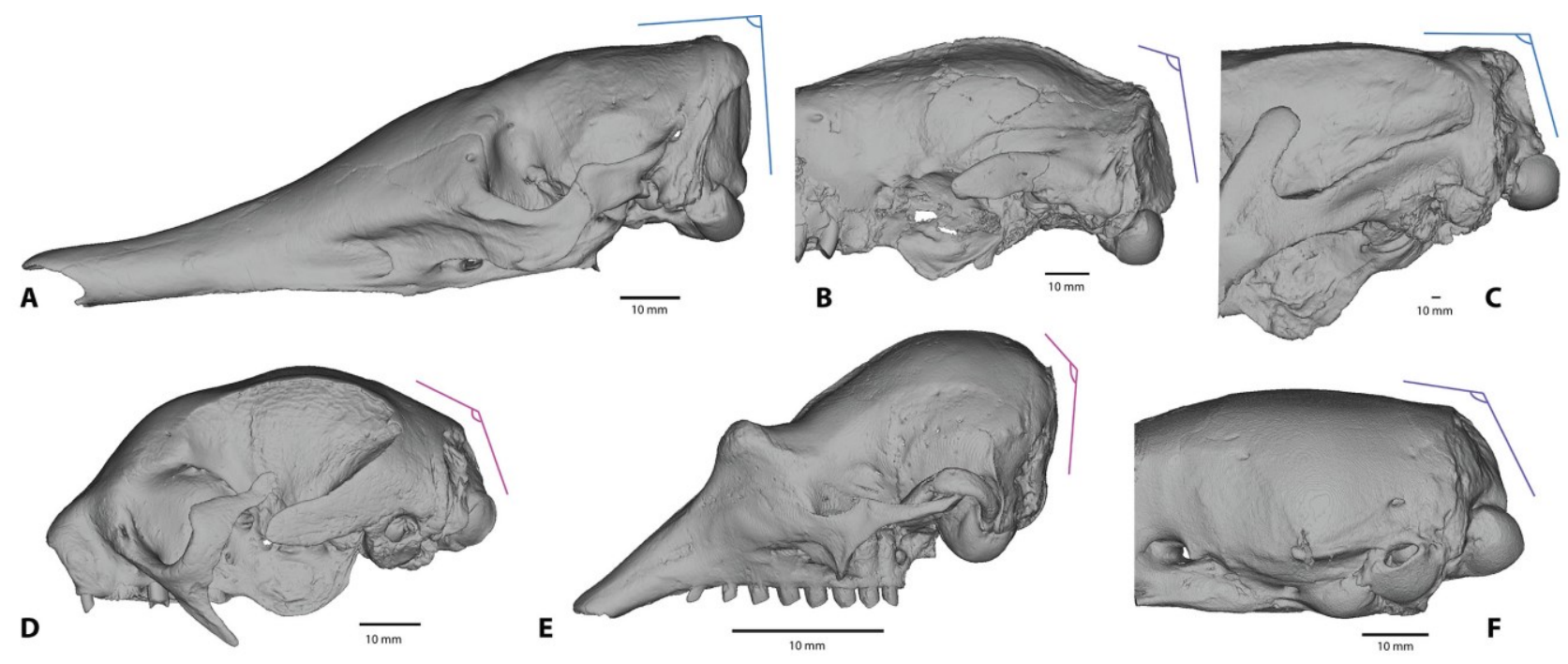

Figure 6. Lateral view of selected xenarthran skulls showing the shape of the posterior cranial vault and nuchal fossa. Colours indicate the acuteness of the angle between the posterior part of the 
cranial vault and the occipital face in the vicinity of the nuchal fossa. A, Dasypus kappleri, USNM 388210; B, Pelecyodon cristatus, MNHN.F.SCZ 204; C, Megatherium americanum, MNHN.F.PAM 296; D, Bradypus tridactylus, MNHN.ZM.MO 1999-1065; E, Chlamyphorus truncatus, IRSNB 6217-324; F, Tamandua tetradactyla, UMZC E582 (see S-Appendix 1 for details on specimens).

A

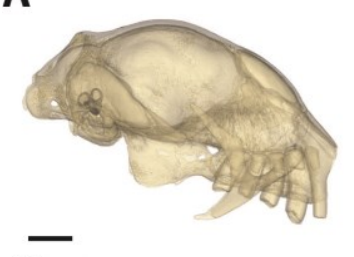

B

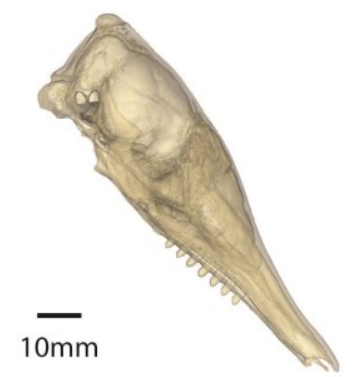

C

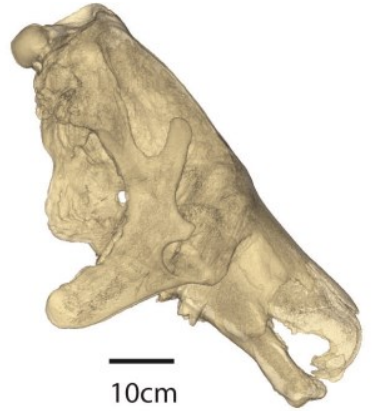

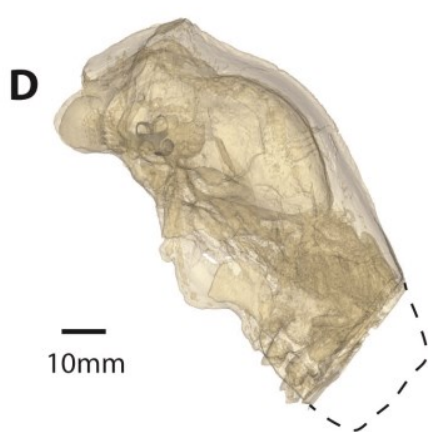

Figure 7. Lateral view of selected xenarthrans skulls oriented with a horizontal LSC. A, Bradypus variegatus, RH 165; B, Dasypus hybridus, USNM 96511; C, Megatherium americanum, MNHN.F.PAM 276; D, Pelecyodon cristatus, MNHN.F.SCZ 204.

\section{Supplementary Information}

S-Appendix 1: Information on scanned specimens and CT-scan parameters.

S-Appendix 2. Illustration of the method used to trace the LSC plane in xenarthrans (see Material and Methods for details). A, virtually reconstructed bony labyrinth of Bradypus variegatus with the reference line used for the measurement of LSC inclination in 13 of the 16 specimens of extant sloths studied; B and C, virtually reconstructed bony labyrinth of Zaedyus pichiy showing the three reference points used for all other specimens studied.

S-Appendix 3: Measurements of head inclination in living Xenarthra and information on data 
source.

S-Appendix 4: Illustration of the method used for the measurement of head inclination; example for an individual of Euphractus sexcinctus.

S-Appendix 5. Dated phylogenetic tree of Xenarthra used for the calculation of K index and PICs (see Material and Methods for details).

S-Appendix 6. Covariation between the LSC orientation and caudal cranial shape in the 14 landmark dataset. Top, shape differentiation of the caudal cranium explained by variation in the LSC orientation in the present sample of specimens (see Material and Methods). Bottom, virtual deformations associated with variations of the LSC-basisphenoid angle, on the extreme sides of the Angle Shape Vector axis, in lateral, medial, dorsal and posterior views respectively. Taxonomic abbreviations same as in Figure 2. 